\title{
Ernest Rutherford his genius shaped our modern world
}

— I.J. Douglas MacGregor - School of Physics and Astronomy, University of Glasgow - UK - DOI: 10.1051/epn/2011503

\begin{abstract}
2011 marks the $100^{\text {th }}$ anniversary of the publication of Rutherford's seminal paper [1] which first identified the atomic nucleus and its essential role in the structure of matter. This crucial discovery marked the birth of nuclear physics and lead to enormous advances in our understanding of nature. Rutherford's legacy has profound and far reaching influences on the shape of the modern world we live in.
\end{abstract}

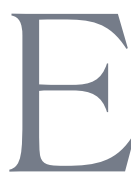

rnest Rutherford was born on $30^{\text {th }}$ August 1871 in Spring Grove, near Nelson, New Zealand. His father, James was a farmer who had emigrated from Perth, Scotland, and his mother, Martha Thomson, was a school teacher from Essex, England. In 1893 Ernest graduated with an M.A. from the University of New Zealand in Wellington and gained a B.Sc. the following year. He was awarded a prestigious "1851 Exhibition Scholarship" to work as a research student at the Cavendish Laboratory, Cambridge, under J. J. Thomson. In 1898 he took up a chair at McGill University, Montreal, where he worked till 1907. He moved back to the UK, to accept the Langworthy Professorship at Manchester University, where he carried out his most famous work. In 1919 he returned to Cambridge as an inspirational leader of the Cavendish Laboratory, building up its reputation as an international centre of scientific excellence. He was awarded the Nobel Prize for chemistry in 1908 and was knighted in 1914 . He was president of the Royal Society 1925-30 and became Lord Rutherford ( $1^{\text {st }}$ Baron of Nelson) in 1931. He died on October $19^{\text {th }} 1937$ in Cambridge. The radioactive element Rutherfordium ( $\mathrm{Rf}, \mathrm{Z}=104$ ) was named in his honour, sixty years after his death.

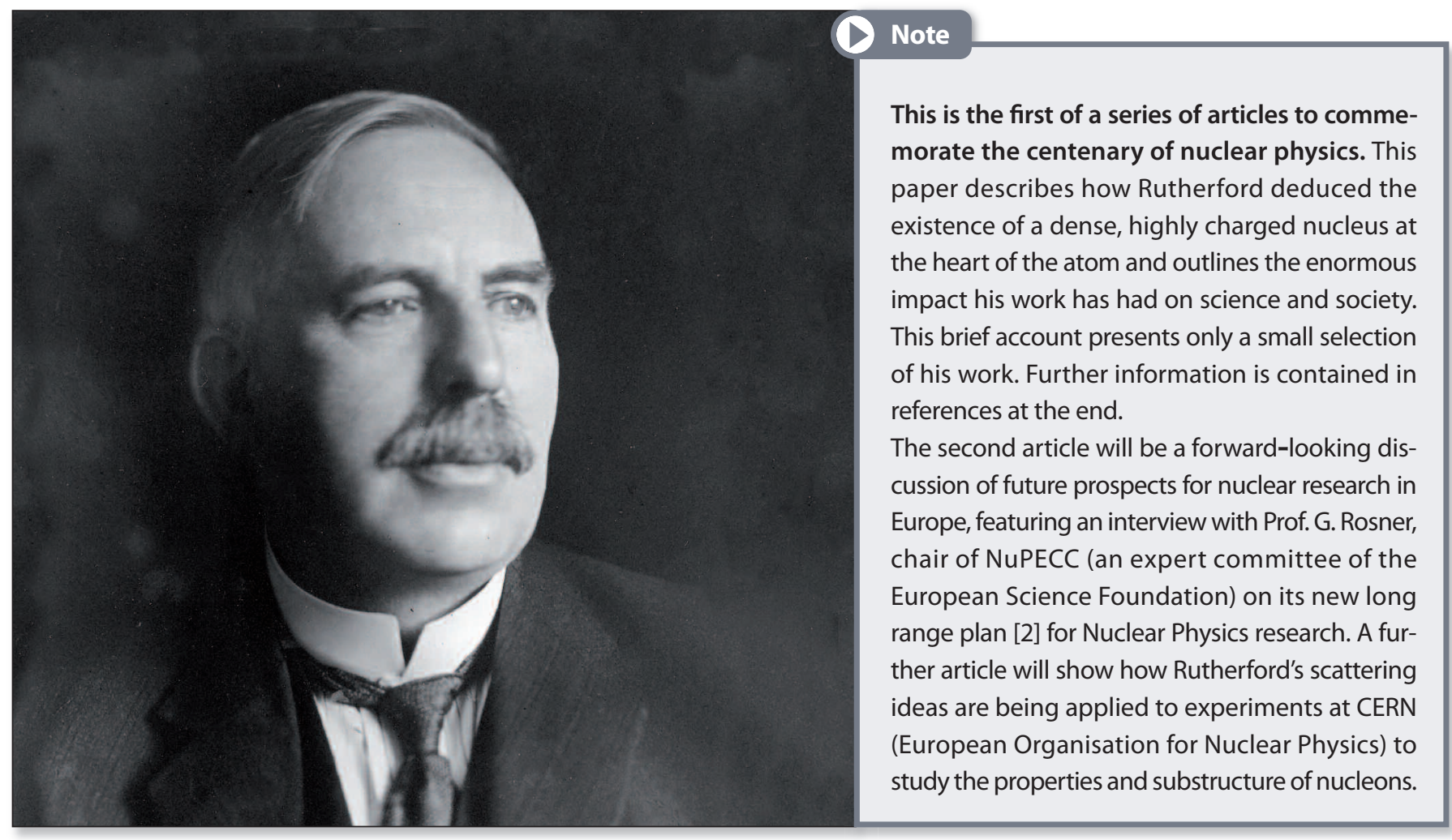




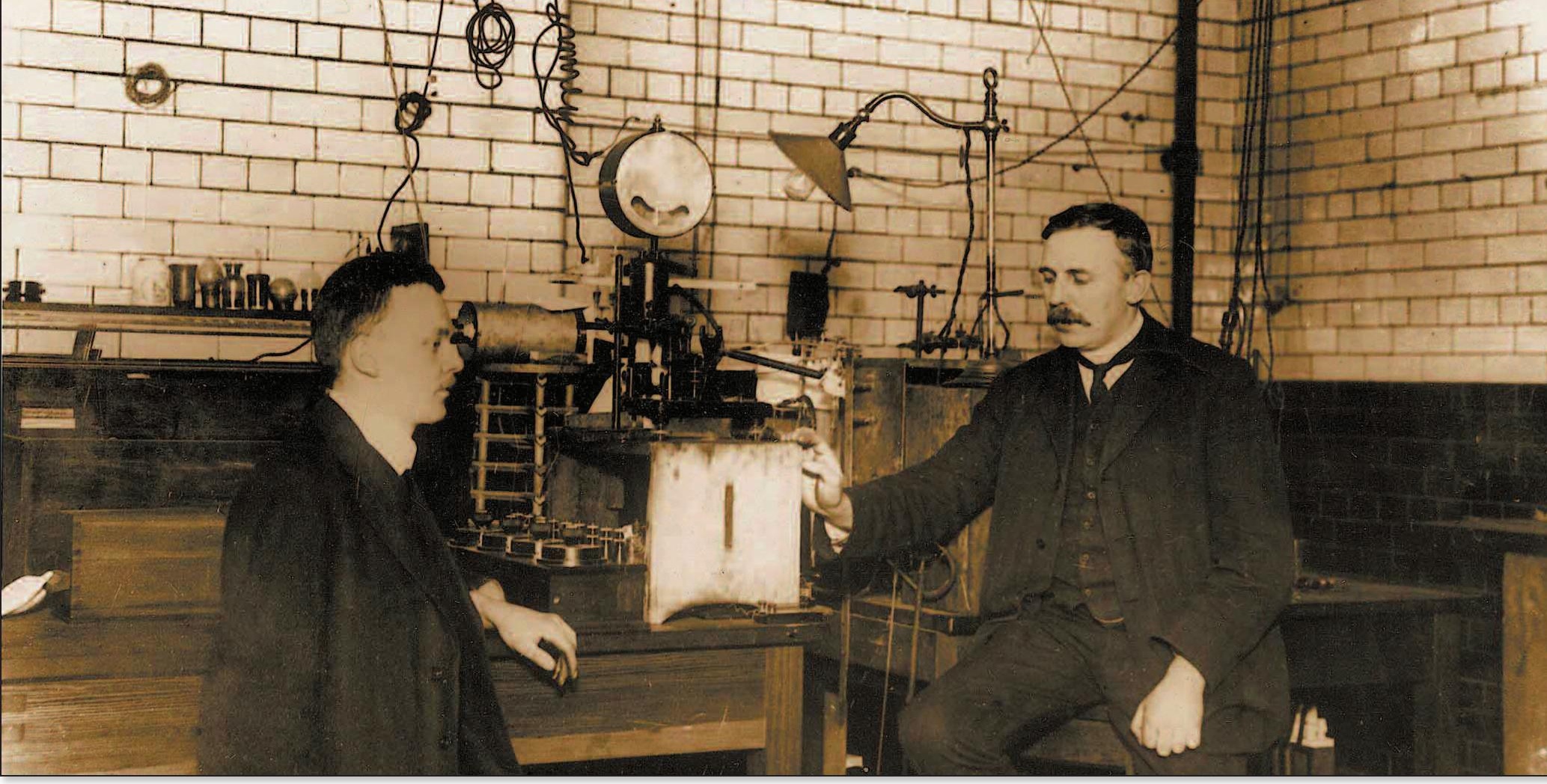

\section{Rutherford's model of the atom}

Rutherford published his model of the atom [1] in 1911 as an interpretation of the $\alpha$-scattering work carried out by Geiger and Marsden [3] two years earlier. The puzzle centred on finding a convincing explanation for the small fraction of a particles (around 1 in 20,000) which were deflected through large angles, after passing through gold foil only $0.00004 \mathrm{~cm}$ thick. He argued that the probability of occasional largeangle scatters was inconsistent with multiple small angle scattering, and could only be explained by a single scattering event. This required an "intense electric field" and led him to propose his model of an atom with a charge of $\pm N e$ at its centre surrounded by a uniformly distributed sphere of the opposite charge.

His arguments did not depend on the charge at the centre, but he chose the correct sign: “...the main deductions of the theory are independent of whether the central charge is supposed to be positive or negative. For convenience, the sign will be assumed to be positive." He was aware that there were unanswered questions about how such a structure could exist: "The question of the stability of the atom proposed need not be considered at this stage..." These questions were only fully answered much later. Using a reasonable estimate for the nuclear charge he calculated the distance of closest approach $(\sim 34 \mathrm{fm})$ for a typical head-on a particle to be completely stopped and provided the first ever order-of-magnitude estimate of the size of the nucleus. He showed that the trajectory taken by an a particle was hyperbolic and related the angle of deviation $\delta$ to the perpendicular distance $b$ between the line of approach and the centre of the nucleus. He showed the scattering probability was proportional to $\operatorname{cosec}^{4}(\delta / 2)$ and inversely proportional to the $4^{\text {th }}$ power of velocity. An important test of his model was to calculate the dependence of the relative number of scattered particles $\mathrm{n}$ on the atomic weight $\mathrm{A}$. The ratio $n / \mathrm{A}^{2 / 3}$ should be constant. The measured values for eight elements between $\mathrm{Al}$ and $\mathrm{Pb}$ ranged from 208 to 250 with an average of 233. He concluded: "Considering the difficulty of the experiments, the agreement between theory and experiment is reasonably good."

Following the publication of his ground-breaking paper [1], Rutherford worked closely with other leading physicists of the day. Niels Bohr visited Manchester in 1912 and again 1914-16. Bohr's model of stationary non-radiating electron orbits [4] added credence to Rutherford's atom and answered the question of why the electrons do not fall into the nuclear core. Subsequent developments in the theory of quantum mechanics gave this an even sounder footing. However, understanding the small size and strong binding of the nucleus would have to wait till the 1930s, when the neutron was discovered and Yukawa first described the strong attractive force binding neutrons and protons together in terms of meson exchange.

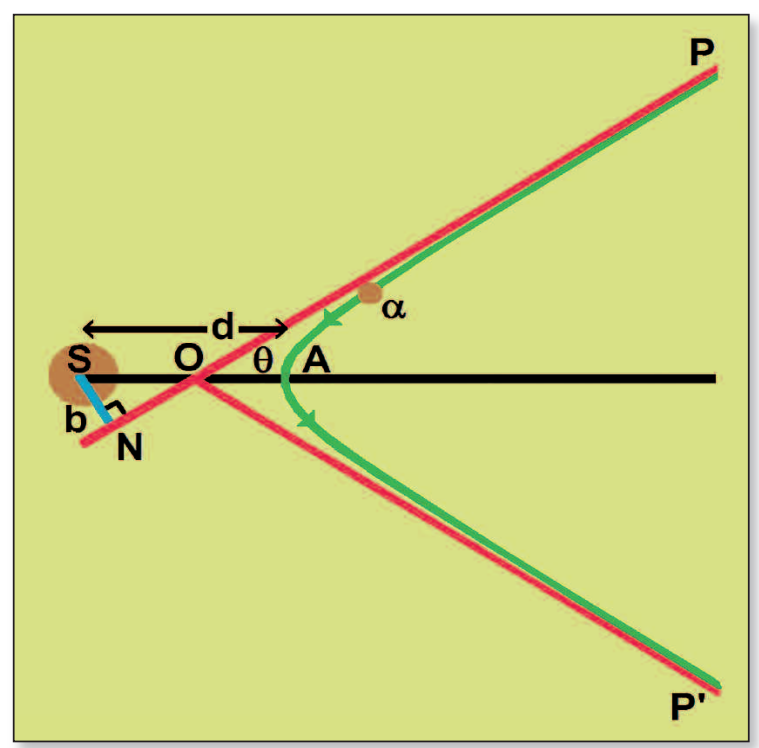

$\Delta$ FIG. 1: Photograph of Hans Geiger (left) \&Emest Rutherford (right) in their laboratory at Manchester University circa 1908.

$\triangle$ FIG. 2: The a particle, experiencing an inverse square repulsive force, follows a hyperbolic trajectory (green) as it approaches the nucleus located at $\mathrm{S}$, the external focus of the hyperbola. It enters along the asymptotic direction PO (red) reaching its closest approach $\mathrm{d}=\mathrm{SA}$ at the apse of the hyperbola before exiting along the second asymptote OP'.

The angle of deviation $\delta=\pi-2 \theta$ depends on the energy of the alpha particle and its impact parameter $b=S N$. 
- While Rutherford carried out $(\alpha, p)$ reactions, changing the elemental composition of the target, the term "splitting the atom" is more usually associated with nuclear fission. In 1934 Fermi carried out experiments bombarding Uranium with neutrons. The results of this early work were not clear. However in 1938 Hahn and Strassmann reported detecting Barium in the products of similar experiments. This was subsequently interpreted by Meitner and Frisch as nuclear fission. The extraction of large amounts of energy from the $\nabla$ TABLE 1 Nobel Prizes for work in atomic structure, nuclear physics, quantum physics or fields which have developed out of nuclear physics. Physics Prizes are in grey and Chemistry prizes in blue. fission process required the development of a chain reaction process. This was researched during the second world war and resulted in the production of nuclear weapons. Later, in 1951, electricity was generated from a nuclear reactor and the phrase "atoms for peace" gained wide currency.

These world-changing facets of nuclear physics were not developed until after Rutherford's death. However, Al-Khalili [5] has discussed whether Rutherford was aware of the possibilities. In the early 1930's Rutherford

\begin{tabular}{|c|c|c|c|}
\hline Year & Recipient & Year & Recipient \\
\hline 1901 & W. Röntgen & 1954 & M. Born \& W. Bothe \\
\hline 1902 & H. Lorentz \& P. Zeeman & 1955 & W. Lamb \& P. Kusch \\
\hline 1903 & H. Becquerel, P. Curie \& M. Curie & 1957 & C. Yang \& T-D. Lee \\
\hline 1908 & E. Rutherford & 1958 & P. Cherenkov, I. Frank \& I. Tamm \\
\hline 1911 & M. Curie & 1959 & E. Segrè \& 0 . Chamberlain \\
\hline 1917 & C. Barkla & 1960 & D. Glaser \\
\hline 1918 & M. Planck & 1961 & R. Hofstadter \& R. Mössbauer \\
\hline 1921 & A. Einstein & 1963 & E. Wigner, M. Goeppert-Mayer \& H. Jensen \\
\hline 1921 & F. Soddy & 1964 & C. Townes, N. Basov \& A. Prokhorov \\
\hline 1922 & N. Bohr & 1965 & S-I. Tomonaga, J. Schwinger \& R. Feynman \\
\hline 1922 & F. Aston & 1967 & H. Bethe \\
\hline 1927 & A. Compton \& C. Wilson & 1968 & L. Alvarez \\
\hline 1929 & L. de Broglie & 1969 & M. Gell-Mann \\
\hline 1932 & W. Heisenberg & 1975 & B. Mottelson \& J. Rainwater \\
\hline 1933 & E. Schrödinger \& P. Dirac & 1976 & B. Richter \& S. Ting \\
\hline 1934 & H. Urey & 1979 & A. Salam \& S. Weinberg \\
\hline 1935 & J. Chadwick & 1980 & J. Cronin \& V. Fitch \\
\hline 1935 & F. Joliot-Curie \& I. Joliot-Curie & 1983 & S. Chandrasekhar \& W. Fowler \\
\hline 1936 & V. Hess \& C. Anderson & 1984 & C. Rubbia \& S. van der Meer \\
\hline 1938 & E. Fermi & 1988 & L. Lederman, M. Schwartz \& J. Steinberger \\
\hline 1939 & E. Lawrence & 1990 & J. Friedman, H. Kendall \& R. Taylor \\
\hline 1943 & 0.Stern & 1991 & R. Ernst \\
\hline 1944 & I. Rabi & 1992 & G. Charpak \\
\hline 1944 & 0. Hahn & 1994 & B. Brockhouse \& C. Shull \\
\hline 1945 & W. Pauli & 1995 & M. Perl \& F. Reines \\
\hline 1948 & P. Blackett & 1999 & G. 't Hooft \& M. Veltman \\
\hline 1949 & H. Yukawa & 2002 & R. Davis, Jr., M. Koshiba \& R. Giacconi \\
\hline 1950 & C. Powell & 2004 & D. Gross, D. Politzer \& F. Wilczek \\
\hline 1951 & J. Cockroft \& E. Walton & 2008 & Y. Nambu, M. Kobayashi \& T. Maskawa \\
\hline 1952 & F. Bloch \& E. Purcell & & \\
\hline
\end{tabular}

said "anyone who expects a source of power from the transformation of these atoms is talking moonshine" Certainly this is true for a single reaction. It requires a chain reaction to transform the scenario. Al-Khalili notes that Rutherford took a close interest in the work of Fermi and Bohr and reports some comments he made which confirm Rutherford was aware of the possibilities of extracting energy from atoms.

\section{Nobel Prizes}

Nobel prizes are the ultimate accolade for scientific discovery. Atomic structure lies at the boundary between Physics and Chemistry and prizes in both subject areas have been awarded for atomic and nuclear research. It is somewhat surprising that Ernest Rutherford did not receive a Nobel Prize for his work on the structure of atoms. He did, however, receive the 1908 Nobel Prize for Chemistry [6]. This was in recognition of his earlier work into the disintegration of the elements and the chemistry of radioactive substances.

However, the true importance of Rutherford's contribution can be gauged by the fact that 8 Nobel Prizes in Chemistry and over 50 in Physics have been awarded for work directly related to atomic structure, nuclear physics, quantum physics and other fields which have developed from nuclear physics (see table 1).

Rutherford worked closely with many of the leading scientific brains of the early $20^{\text {th }}$ century (J.J. Thomson, R.B. Owens, F. Soddy, O. Hahn, H. Geiger, E. Marsden, N. Bohr, H.G. Moseley, G. de Hevesy, A. Szalay, J. Chadwick, P. Blackett, J. Cockroft, R. Walton, G.P. Thomson, E.V. Appleton, C. Powell, F.W. Aston, C.D. Ellis and others). This close interaction played an important part in the rapid development of physics during and after his lifetime. It is reported in [6] that he played an influential role at the Cavendish "steering numerous future Nobel Prize winners towards their great achievements". It is clear that Rutherford was present at the heart of a very large number of fundamental scientific discoveries.

\section{Rutherford's legacy}

Rutherford's work provided the key to an exciting new world of science and applications. The physics of the atom is governed by the rules of quantum physics, taking us into domains classical physics cannot predict or describe. This has produced a step change in our understanding of nature and a host of previously unimagined applications. As studies advanced our understanding of atoms, chemical elements, radioactivity and isotopes has been transformed.

Milestones in the development of nuclear science included the discovery of the neutron, the positron and antimatter. The field of particle physics was spawned as a separate research discipline. Energy production 
in stars and the creation of light and heavy elements in stellar processes rely on nuclear reactions. Direct applications such as medical imaging have transformed the diagnosis of disease and radiotherapy has advanced the treatment of cancer. Detector and accelerator technologies have found wide application in industry. The fields of solid state physics, electronics, computing and modern optics all depend on quantum physics which was initially developed to explain phenomena in nuclear and atomic systems. The Institute of Physics (IOP) has commissioned a report "Nuclear physics and technology - inside the atom" [7] which details the impact on society of research into the atomic nucleus. There is scarcely an area of modern physics which does not owe a debt of gratitude to Ernest Rutherford.

\section{Celebrations of Rutherford's Achievement}

Many events have been organised to celebrate the centenary of Rutherford's famous publication[1] .The EPS Nuclear Physics Division has commissioned a website [8] to collate information on this notable anniversary. A reception, bringing together politicians and scientists, was held in the House of Commons on 29th March 2011. The reception was hosted by E. Vaizey M.P., whose constituency includes the Rutherford Appleton Laboratory, and sponsored by the New Zealand High Commission, the IOP, and the UK STFC Research Council. Ernest Rutherford's family was represented by his great granddaughter, Prof. M. Fowler. Speakers from science (Prof. B. Cox), the IOP (Dr. B. Taylor), politics (E. Vaizey M.P.) and diplomacy (D. Leask, the New Zealand High Commissioner) highlighted the sheer genius of Rutherford in unlocking the structure of the atom. At the event the STFC announced the creation of the Ernest Rutherford Fellowship Scheme to support early-career researchers in the UK [9].

On $5^{\text {th }}$ April 2011 Al-Khalili gave a highly acclaimed public lecture [5] on "Nuclear Physics since Rutherford" at the IOP Nuclear and Particle Physics Divisional Conference, in Glasgow. This conference brought together many separate scientific disciplines which owe their origins to Rutherford's work. The Rutherford Appleton Laboratory, which takes its name from the two scientific pioneers, Ernest Rutherford and Edward Appleton, organised a Schools meeting on $19^{\text {th }}$ May 2011, where Al-Khalili was again the guest speaker.

The main celebration was the Rutherford Centennial Conference [10] (Manchester, 8-12 August 2011). This brought the commemorations back to the city where Ernest Rutherford carried out his pioneering work. The conference highlighted the anniversary with talks by leading international speakers on a wide range of topics which have developed out of Rutherford's work.

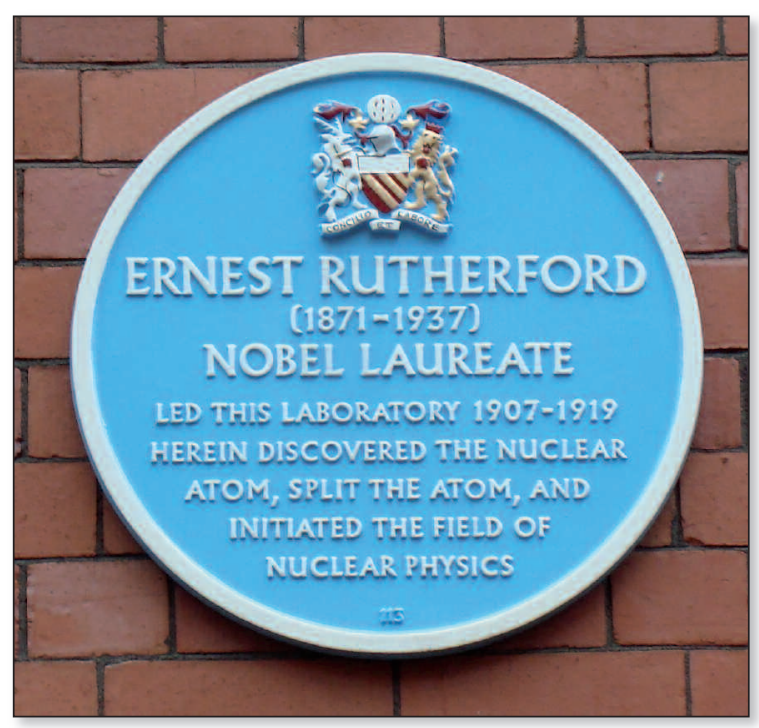

4 FIG. 3:

Blue Plaque at Manchester University commemorating the achievements of Ernest Rutherford.

\section{Acknowledgments}

The author is grateful to Profs. S. Freeman, J. Al-Khalili and M. Fowler for information about the life and work of Ernest Rutherford. Photographs are provided courtesy of the University of Manchester and Barry (Bazzadarambler) who posts on flickrø.

\section{About the author}

Douglas MacGregor is a reader in Nuclear Physics at the University of Glasgow. He serves on the Rutherford Centennial Conference organising committee, is secretary of the EPS Nuclear Physics Division and chairs the IOP Nuclear and Particle Physics Division.

\section{References and Further Reading}

[1] E. Rutherford, Phil. Mag. 21 (1911) 669.

[2] Ed. G. Rosner et al., www.nupecc.org/index.php?display= Irp2010/main.

[3] H. Geiger and E. Marsden, Proc. Roy. Soc. 82 (1909) 495.

[4] N. Bohr, Phil. Mag. 26 (1913) 1; 476; 857.

[5] J. Al-Khalili, Nuc. Phys. News 21, in press.

[6] The Nobel Prize in Chemistry 1908, http://nobelprize.org/ nobel_prizes/chemistry/laureates/1908/rutherford-bio.html.

[7] Ed. N. Hall, IOP report (2010), www.iop.org/publications/iop/ 2010/page_42529.html.

[8] World Year of the Nucleus 2011 website, http://wyn2011.com/en/.

[9] STFC Ernest Rutherford Fellowship scheme, www.stfc.ac.uk/Funding+and+Grants/509.aspx.

[10] Rutherford Centennial Conference website, http://rutherford.iop.org.

[11] E. Chadwick and J. Chadwick, Ernest Rutherford Obituary, Obituary Notices of Fellows of the Royal Society, Vol. 3 (1936-1938).

[12] Ed. J. Chadwick, The collected papers of Lord Rutherford of Nelson, Vols. 1-3, Allen \& Unwin (1962).

[13] W.E. Burcham, Rep. Prog. Phys. 52 (1989) 823.

[14] W. Marx, M. Cardona and D.J. Lockwood, Phys. Can. 67 (2011) 35.

[15] M. Thoennessen and B. Sherrill, Nature 473 (2011) 25. 